\title{
Un poeta hondureño: Juan Ramón Molina.
}

\begin{abstract}
Texto de la conferencia pronunciada en Tegucigalipa por el Dr. Enrique Peña Barrenechea, catedrático de esta Facultad, defiriendo a una invitación del Instituto Hondureño de Cultura Interamericana.
\end{abstract}

Estimado auditorio:

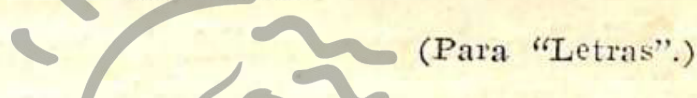

Aceptando una atenta invitación del Instituto Hondureño de Cultura Interamericana que agradecemos profun-

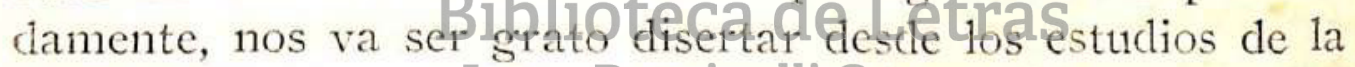
H. R. N. sobre la peesige peufraine Ramonvarenta.

Hermosa iniciación tuvo este ciclo de conferencias con las palabras del señor Ministro de México, Profesor Luis Chávez Orozco, que hicieron destacar aspectos de tal trascendencia de la personalidad de Francisco Morazán que ellas habrán de constituir, para siempre, uno de los votos más fulgurantes en homenaje del Catidillo.

Hubiéramos querido desarrollar un tema que se halla aclimatado en nuestro espíritu desde hace algún tiempo, o sea el que se refiere a la permanencia de Morazán en nuestra patria. Motivo de hondo halago ha sido para nosotros desde que llegamos a esta generosa tierra escuchar muchas 
veces midos los nombres de Morazín y del L'erí por la circunstancia de haberse dirigido el gran patriota a Lima después que las fuerzas separatistas del General Carrera hubieron de vencerle en Guatemala.

En la Capital del Perí halló la comprensión y el afecto de notables personajes. Era la época en que Francisco de Paula Vigil, el anatematizador de Gamarra, publicaba su "Defensa de la Autoridad de los Gobiernos contra las Pretensiones de la Curia Romana" y como señala Jorge Guillermo Leguía - mo de sus más puntuales biógrafos- "los liberales del viejo mundo y principalmente los liberales hispanoamericanos contemplaban en él un caso de excepción en los anales doctrinarios del nuevo continente y le rinden fervoroso e indiscutible homenaje". Si como dice, asimismo, Leguía, Vigil es la personalidad que mís atrae en el Perí a los viajeros ilustres como después don Ricardo Palma a los literatos y Mantel Gonzáfez Pradta (tan fervorosannente recordado en nuestros lías por el hondureño Rafael Heliodoro Valle) a los espífitus (le vanguardia, sin duda alguna ef alma morazánica captó de la de Vigil matices de tal significado que bubieriontecandede atlos gle su sueño de libertad que quiso definitivamente dolamer en su fracasada campaña restauradora.

Eran los días, también, en que Bartolomé Herrera adquiría por oposición el curato de Lurín, y en los que empezaba a reemplazar - tan señera figura de nuestra Patrialos errores jansenistas que en religión y en politica había asimilado, por la austera disciplina preconizada por la Compañía de Jesús y que llevara en un cercano futuro a devolver al Convictorio de San Carlos - cuando ejerce su Rectorado- el prestigio que tenía en los mejores días de la Colonia, prestigio que aún supera por una radical reforma cuyas principales innovaciones han de referirse a las ciencias fi- 
losóficas y juridicas que suceden al orden escolástico hasta entonces imperante.

Era el tiempo en que Ricardo Palma nuestro "mago cordial”, según la feliz expresión de José Gálvez, atisbaba, perplejo, desde el mirador de su infancia el paisaje espiritual de su ciudad y escuchaba las consejas y leyendas que hubieron de transfigurarse después por el don de su genio expresivo en la literatura inmortal de sus "Tradiciones" a las que una infinita progenie de virreyes, damas, frailes, comiquillas, tunantes y pecheros aportó el clarobscuro de su sonrisa y de su intriga.

Eran, en fin, los días que presentaban entre el fervor de "los enamorados de la trágica gloria de Salaverry, los partidarios de la Confederación y los nacionalistas recalcitrantes que no veían con buenos ojos of triunfo de Gamarra apoyado por las fuerzas ce Bulges" langracia turbadora de la limeña que cubría su rostro con el rebozo y a la que Max Radigut — viajero de la época- dedicara - como un siglo después su compatriota Paul Morand- tan sugestivas palabras.

Estos son algunos de los matices ce la c1udad en la que vivió Morazán por ciefto tiempo. Para enfocarlo con toda precisión en tal ambiente sería necesario una búsqueda personal en los archivos y bibliotecas de la Patria; una documentación que otorgara a nuestra charla el único valor al que podría aspirar y que si no la desarrollamos ahora no renunciamos al deseo de poder abordarla en otra época. Pero sí queremos adelantar descle este instante nuestro homenaje al mártir de la Federación por cuyo sueño y obra vivirá para siempre en el corazón de los hijos de América. 
Al arribar hoy al paisaje de un poeta creemos que no. resultan por cierto nubladas nuestras intenciones de acercarnos, aún más, al alna de Honduras, porque un poeta de la talla de Juan Ramón Molina (aún con los defectos que una estricta e imparcial crítica ya ha encontrado en su obra) pensamos que también constituye un puro símbolo de nacionalidad. No es necesario que para que lo sea haya entonado estrofas de vibrante repercusión cívica; un verdadero poeta, aún por ajenos que le sean los motivos nacionales, es ya un personaje de selección, una de las lámparas inapagables que ornan el retablo de su pueblo. Y Molina atalayando constantemente su intimidad dió, al mismo tiempo, estrofas en las que el fervor por las glorias de su tierra - en seres y en paisajes - representa wina de sus facetas primordiales.

Lo dicho sea, pues, paya Har nuestro tema como continuación de un cielo de fadianteg figuras.

Y ahora entremos con unción en el bosque de su poesía que no es otro el stmil que se nos ocurre para hablaros de ella. Bosque de sombra y luz de melodía y de estrépito, de floración extyberante y de franciscanas florecillas, pero imperando siempre sofre Gatn opuestas manifestaciones ese es-

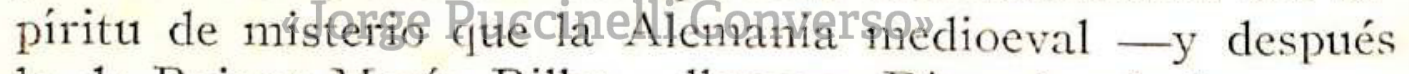
la de Rainer María Rilke- llamara Dios al referirse, precisamente, al secreto de los bosques.

Nos encontramos ya ante tres aspectos del alma de Molina: el de su exaltación por el paisaje patrio; el de su intimidad amorosa y el de su sentimiento religioso que es como otra amplia sala de la de aquélla o sea de su castillo interior. Es decir, exploración incansable hacia un ideal. Los signos de su ruta serán los mismos de los líricos inefables desde Ossian hasta Stefan George: la soledad, el silencio, el mar, la noche, las aves, las flores y el amor y la muerte. Los procedimientos para expresarlos serán distintos con las imper- 
fecciones propias de un poeta americano que como él, salvo contadas y fugaces veces, no supo del contacto con otros seres y otros estímulos, o acaso fiel a su rebeldía innata- o más bien por su vida tan breve, tampoco supo de una disciplina cultural que hubiera contrapesado el avasallador impulso de su espiritu.

Victoria Ocampo nos habló alguna vez en sus páginas cle "Sur" sobre la Condesa de Noailles. Recordaba en ellas ctras del "Orlando" de Virginia Woolf, o sea las que se refieren a la inquietud que tenía una niña inglesa por conocer al poeta Pope y cómo ese su estremecido ensueño, esa imperativa obsesión de su vida se volvió realidad una tarde en la que el propio Pope le ofreció un asiento en su coche al salir de una casa donde se hallaban los dos de visita. La adolescente admiradora que no acertaba por la emoción a clespegar los labios durante el recorrido que hiciera el carruaje, agudizaba, en cambio, sus miradas cuando de trecho en trecho un candil callejero echaba luz en la sombría concavidad del vehículöèn donde cse encontrabansy cuenta la ilustre escritora inglesargue úc cadalli insólita sluminación de la penumbra iba la niña descubriendo serias imperfecciones en aquél que hasta entonces había sido para ella la misma reencarnación apolínea, decepcionándose del todo cuando al llegar la carroza a su destino una total luz le acabó de presentar a su poeta.

Hemos recordado este pasaje porque parece que es con él con el que quiere también afirmar la autora de "De Francesca a Beatriz" st pensamiento de que el artista debe interesarnos sólo por su obra y que es el mismo que Enrique González Martínez expone en las páginas que escribió para la segunda edición de las poesías de Molina que llevan el waltwithmaniano título - que también lo fué de la que en I9 I I hiciera Froylán Turcios- de "Tierras, Mares y Cielos" y 


\section{$-328-$}

que llevó a cabo con tan celoso empeño nuestro inolviclable amigo Ismael Zelaya.

Porque ese atisbo incesante que de la matcria humana hacía la niña inglesa de su principe puede corresponder al afán de otros por referirse a la anécdota de 111 artista de quien interesa sólo al citado e imponderable esteta mexicano "la materia lírica amasada en la realidad o en el ensueño, elaborada a fuerza de hurgar en el propio enignia interior o lograda en ansias evasivas de superación".

$Y$ es esa, también, nuestra posición ante el artista, aunque sabemos que descle el Padre Homero la condición de aventura, es decir la anécdota, la vida fué y es uno de los signos que presiden la obracte arte.

Por eso no seguiremos, ahora, las megalomanias de Molina, ni sus desclenes de sultan y contradiciendo estos aspectos sus singulares actitudes de niño, sino que nos situamos en su bosque poético, sínul éste que también lo fué de la escuela romántica de la que preferentemente se nutrió: romanticismo de España, o mejor dicho romanticismo de Ané-

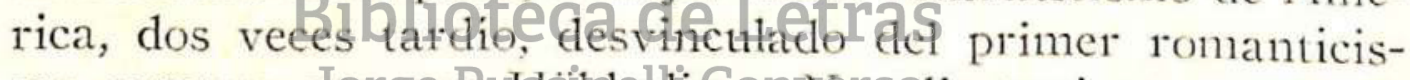

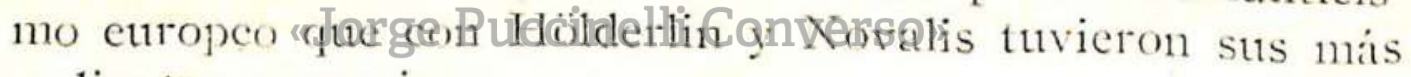
radiantes expresiones.

Un viaje con escalas por el paisaje de los post-románticos del Continente nos haría precisar en todos ellos la misma estridencia verbal, el mismo alarde expresivo, asi como el sincrónico suspiro. Les es común una melancolia importada. Pocos, muy pocos, nos darían la impresión, al retornar de él, de que contribuyeron a la estabilización de un nuevo espíritu en la poesía como fué el advenimiento del Modernismo. Y Molina perteneció, por cierto, a aquéllos que supieron en un momento dado distinguir en su bosque la pura flor de los matices de la de aquella otra de agresivos colores. 
Ia han sido estudiados con toda amplitud los diversos factores que concurrieron a la creación de la nueva sensibilidad. Blanco Fombona, exégeta del modernismo americano, nos habló de la conjunción del romanticismo con el parnasianismo, tendencias antitéticas - dijo- cuyo avenimiento parece absurdo e imposible, y nos presentó la progenie que aportaba tan hermoso mensaje de la que se destacaba "como el más evidente paradigma de la influencia conjunta del romanticismo y del parnaso", el cubano Julián del Casal cuya poesía calificaba como la flor romántica del parnasianismo.

Es, pues, a tal movimiento iniciado como lo observa el mismo Fombona coincidentemente con José Asunción Silva en Colombia, con Julián del Casal en Cuba y con Rubén Darío en Nicaragua al que se stma ávido de una renovación espiritual Juan Ramón Molina solre el que con notoria injusticia ha caído - si lo consideramos fuera de su patriauna espesa niebla de desconociniento o de olvido.

El color y la música elementos primarios del simbolismo - conducen ya a una transfiguración del vocablo que

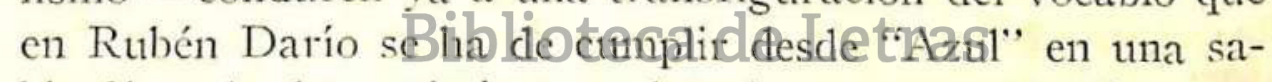

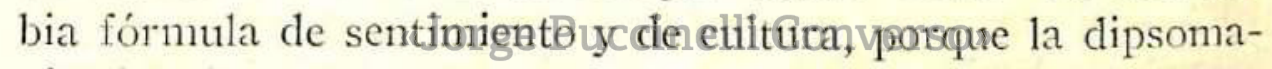
nía del chorotega, su temor por la palabra hablada, su sonambulismo no parece que fuera sino el paradógico sésamo a la puerta de oro que le muestra los recintos de sabiduría estética, si el prólogo de Molina a la inédita novela de Turcios "Annabel Lee" escrito dos años antes de su muterte transparenta un absoluto refinamiento en el pensar y en el sentir, bien nos dice, precisamente, ese prólogo qué elevadas cimas le estaban reservadas para irradiar su nombre al Continente de no haber determinado los dioses la breve órbita de su vida y si hubiera dado a su inteligencia una disciplina 
que por estricto designio -que bien pudo ser el de él- supo en medio de sus torbellinos de angustia dar a la suya el autor de "Cantos de Vida y Esperanza".

Las siempre leidas páginas del Glosario de Xenius nos presentaron un dia a la aventura como problema y a la aventura como incentivo. ¿Dónde encontraremos mejor, se preguntaba D' Ors, el goce del arte, en la sorpresa o en la previsión? La sorpresa excita curiosamente pero en el cumplimiento de la previsión se complace el inimo. Y agregaba: previsión se llama el secreto del ritmo, previsión - no otro nombre - se llama el secreto del verso y de la estrofa". Y la aventura, es decir la vida fué para Molina el deslumbramiento de la sorpresa, la que inspiró en su alma el espontáneo mensaje lírico ossea su romanticismo, y en Dario la complejidad del problenra, elafán y la realización de separar, como un Moisés del verso, del mismo océano, las ondas del silencio de las ondas del estrepito.

Pero como todo mensaje el cle Molina trajo también el sentido de una renovación que es a la que ha aludido la crítica del ilustre mexicano que prologa su libro. Ya a pesar de la rapideß conituteseadvierte hay sido escritos muchos de esos poemas; ya a pesar de la temítica de otros, de sus pueriles adjetivos y reforica - monstruo éste siempre acechante en su bosque como lo estuvo, también, con la afectación, en el dominio forestal de Lugones- se deja entrever al poeta distinto a casi todos de los de la hora y lugar en que vivió, inquieto, preferentemente, por una adaptabilidad a los giros del pensamiento literario francés que como observa Isaac Goldberg son los que influyen más notoriamente en el modernismo americano que tuvo entre sus precursores a Díaz Mirón y a Gutiérrez Nájera. Y ya por esto es Molina el que escruta una lejana y rutilante ciuclad que 
a la que como si en el cuento de Lord Dunsany no ha de arribar su barca, fue, en cambio, un elegido para el goce de verla y de sentirla.

Creemos haber fijado la posición de Molina con relación a su época literaria. Eminentemente sincero, dejó hablar a su corazón; eminentemente inquieto supo, en su momento, estar atento a la renovación precisa que una muerte prematura impidió tomara mayor significàdo.

Si comprimís el libro en vuestras manos en una hora cle meditaciones, quizás tomaría la forma de un corazóndecía Molina al referirse en su Prólogo a la citada novela inédita del animador de "Ariel". Podríamos aplicar sus propias palabras al referirnos a "Tierras, Mares y Cielos". Vibra alli un sentimiento ininterrumpido que ha de tener especial latir en el corazón de los hijos de esta tierra cuando es inspirado por ese conmovedor símbolo de la nacionalidad como es el Padre Reyes o por los paisajes que supo sentir tan intensamente conto el QkíQ Q ande, lâs espesuras de los

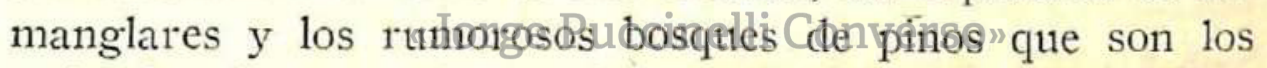
estímulos de su poesía vernácula y por los que exaltó en un poema autobiográfico un roussoniano retorno a las primitivas formas de la naturaleza, aspecto éste que en la poesía del Continente ha de tener altísima realización en José Santos Chocano quien alguna vez hubo de hablar de los poetas nacionales a través de la exaltación de ellos por su paisaje, poetas que (con específica referencia a nuestro ambiente) debían colgar sus versos como las águilas sus nidos, de los nevados picos de los Andes.

Por ello es Molina un poeta nacional, como lo es tam- 
bién -independientemente de sus otros atributos- el Padre Reyes, cuyas Pastorelas nos presentan encantadores cuadros que corresponden al paisaje de su patria, pero los que - justo es reconocerlo- no estín signados con esa exaltación lírica que es el patrimonio romántico de Molina.

Si de esta poesía en cuyo grupo colocamos sus poemas de entonación cívica como "Aguilas y Cóndores" y en especial su "Salutación a los Poetas Prasileros" (que por su ardoroso ímpetu de libertad llamariamos un poema carducciano) pasamos a aquellas otras en las que palpita su intimiclad amorosa y su sentimiento religioso habremos - como lo expusimos al comienzo de esta charla- descrito su total órbita lírica.

Intimidad del amor humano que al consumirse en la llama engendra el fénix de su ferwor religioso. Siente, como Nervo, un intensodolor por tura ausente que si en el dulce amador de Kempis, va a ser el signo característico de considerable parte desu obra lírica, en Molina va a tener en determinados poemas, o acaso en uno solo, un análogo sentimiento de renunciación a lo terreno, una infinita ansia de liberación. Esla-egracesctina mueft en donde el ritmo

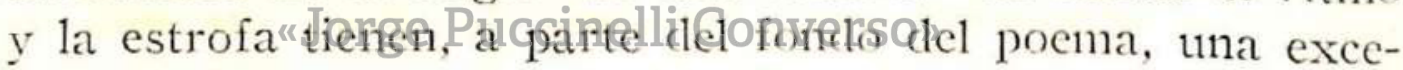
lente caliclad lírica. A pesar de las interrogaciones con que pretende escrutar el Arcano, extićndese una atmósfera de serenidad que no deja de ser contradictoria con el impulso vital que hemos mencionado como dón primordial de su arte, con esa espontancidad desconcertante $y$ turbadora que significa su sino romántico. Es el que estoicamente acata, en medio de su dolor, las disposiciones divinas:

"Señor, nunca discuto tur voluntad, porque eres 
padre y dueño de cosas, espiritus y seres!".

Versos que se hermanan con aquel de Nervo:

"Mi voluntad es única con la Divina Ley".

Ha cumpliclo el poeta con su destino humano de exaltación tremante $y$ de confidencia azorada. Estímulos de la primera han sido el paisaje circundante y su infinita ansia de que se unan todos los corazones "para que baje el ángel de la celeste paz"; de la segunda, las señales que el amor y la muerte ha grabado en su espíritu; amor y muerte que le conducen a Dios, cuya pieclad inmensa es la esencia de ellos.

No importa que ese torsente de sensibilidad que era su alma no supiera siempre del cauce, de tma sabia disciplina estética; de esa tensión constante que un exégeta de Rainer María Rilke - "el más alto ejemplo lírico del siglo"- aludiera al referirse, precisamente, al impetu de su alma y al sosiego de su pluma. No imporla que en la espesura de su bosque haya habido dilatadas distancias para encontrar el prodigio de la flor azth, Aquef Sînbofo têt pensरamiento mís-

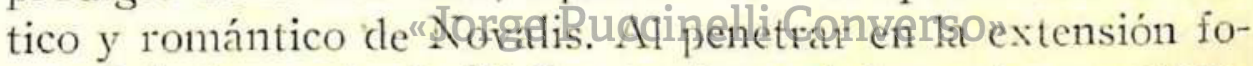
restal de la poesia de Molina tuvimos el deseo de encontrarla, porque sabíamos como el adolescente personaje de una novela del mismo Novalis que sus pétalos eran "diafanidad y vaporosa gorguera", que "el centro, cerúlea, una cara sutil y vacilante" nos miraria, nos miraria para toda la vida. Y la hemos encontrado. Allí está como altísimo ejemplo de la más pura perfección formal, de la más secreta y nostálgica gracia, signado con el pathos de los grandes creadores su "Pesca de Sirenas" que traduce como líricos inefables de todos los tiempos aquel "grito sensual de ansia insatisfecha" que todos sofrenamos; poema en donde el sobresalto anímico, la ondulación pasional, son susceptibles- 
por alto destino- al acatamiento de una disciplina estética. Ya la tonalidad romántica, alentadora en su esencia de la propia entraña del poema, equilibrase con una música y matiz del vocablo que tienen su origen - pero transfigurado por su propio clon creador-en los mejores modelos del parnasianismo francés.

Estas palabras forman la más modesta pero estremecida hoja que queremos poner en la guirnalda de los homenajes que amorosas manos tejieron para la gloria del poeta y a la que José Santos Chocano, - que en cinegética aventura persiguió a la Quimera por estos boscajes del trópico- ofrendó un poema cuyos primeros versos dejan honclamente expresada su emoción:

"Parto yo este soneto para clecir la pena que me trae la muerte del cacique sonoro, cuyßnilaziodecoble ectyetreeha de oro un eg8rdespertaronlquentodascia suena!'.

Maza de roble y flecha de oro. La que agita tremante la diestra: símbolo humano; la que vibra eterna y misteriosa, fugaz y extática en el aire mismo de Zenón de Elea: símbolo del Espíritu.

Tegucigalpa D.-C.-Honduras.-I942.

Enrique Peña Barkenechea. 